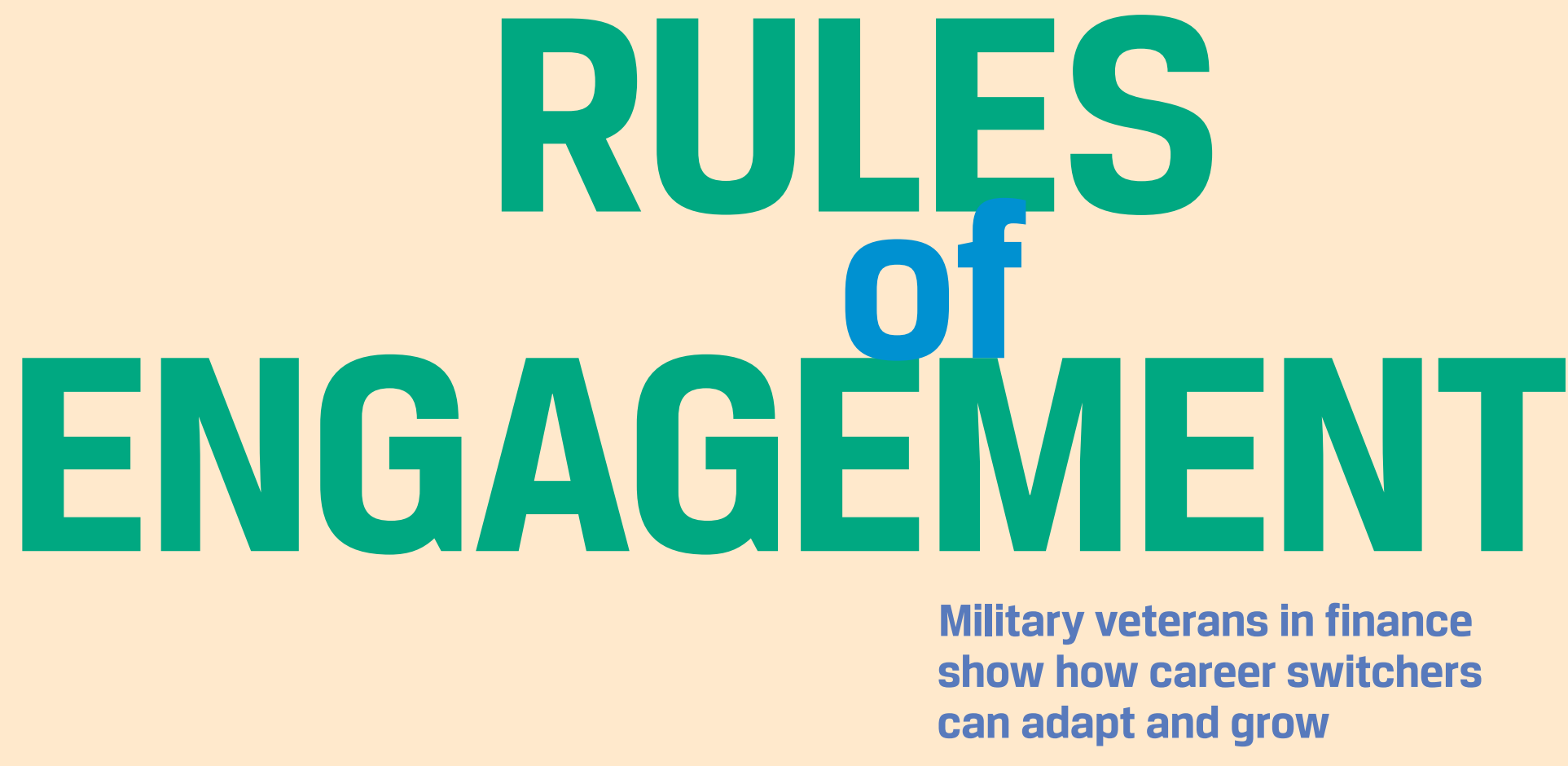

By Lance Widner, CFA (USNR), and Matt Noll, CFA (former USN)

Pathways into the financial services industry can be just as varied and complex as the industry itself. In 2015, three current or prior military service members started the Veterans Roundtable, a special-interest group of the New York Society of Security Analysts (NYSSA), the largest member society of CFA Institute. The idea was to create a platform that gives veterans access to the tools and resources required to transition successfully to a career in finance. Some veterans have already used their military experience to succeed in the industry, and their stories provide examples of how other professionals-not only military veterans - can use different experiences and backgrounds to change career paths and make successful transitions. In this article, four veterans with diverse personal histories and circumstances explain the keys to their success.

\section{BRANDIS DESIMONE}

Managing director, Corporate Client Group at NASDAQ

As a female in two largely male-dominated fields (military and finance), how did you decide to enter each of them?

I began my military career at [the US Naval Academy] in early 2001, before 9/11. The idea of serving my country and doing something bigger and greater than myself was what inspired me to serve. Gender was never something I thought of during the admission process-perhaps it was blind, youthful optimism. However, once at Annapolis and later in the naval service, gender and the awesome responsibility of being a woman was something that I carried with me and thought about each and every day. It still feels like we are on the precipice of gender integration, and it's more important than ever for women in fields like the military and finance to pave the way for others to follow.

As a woman in the Navy, I learned how to walk the fine line of fitting in but without losing my own sense of femininity. My graduating class was the 25th class of women at Annapolis, and there was still a lot of resistance and uncertainty about a woman's role at the school. The 
military also taught me to develop very thick skin. Crossing the Pacific Ocean on a destroyer with a crew of $90 \%$ men will do that to you!

I began my civilian career on the trading floor at Merrill Lynch, which felt like a testosterone-filled combat ship floating above Wall Street. At Merrill, things moved fast, people were often ruthless, and quick decisions had large financial impacts. It was an environment I knew well, and one I knew I could handle. I'm now a managing director at NASDAQ and a mother of two young children. I often question if my daughter will feel the sense of gender responsibility that I carry with me every

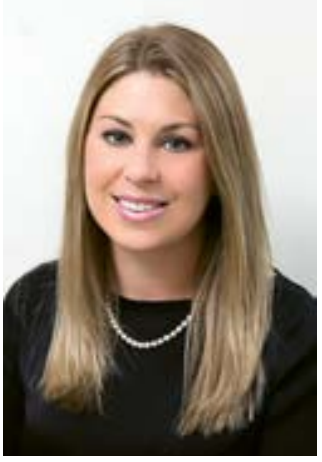

Brandis DeSimone day. I can say with certainty that if she wanted to go into the military or work in finance, I'd absolutely encourage her to do it.

\section{Can you describe your transition out of the service?}

The hardest part about the military-to-civilian transition is learning to ask for help, and I don't think this challenge is gender related. In the service, you learn to fend for yourself, and in the civilian world (especially the financial industry), networking is critical to survival and advancement. It took me a long time to understand that networking was not a sign of weakness. I was able to land my first job on Wall Street solely based on the assistance, guidance, and coaching of fellow veterans who had done the transition themselves.

\section{You've been very involved with NASDAQ's promotion of veteran initiatives. Can you give us some examples?}

Something I promised myself after my experience at Annapolis, in the Navy, and especially during my career transition, was that I would give back to the veteran community once I was able. NASDAQ has afforded me that opportunity. NASDAQ is unique in that we have a massive network of listed companies on our exchange, and it's become apparent that the majority of these companies truly care about veterans and the hiring of service members as they transition into the civilian world and retaining these vets for years to come. For the past five years, we've worked to bring these companies together to share ideas on how they've been successful with their own hiring initiatives. A great testament to this is our annual Veterans Day opening and closing bell ceremony, where hundreds of C-level executives have taken NASDAQ's "veterans hiring pledge." Every year, I am humbled by the number of corporate CEOs that fly across the country on Veterans Day just to be at NASDAQ for this pledge. It's an overwhelming sign of American patriotism that truly takes my breath away and makes me tremendously proud to have served this great nation.

\section{MIKE ZAPATA}

\section{Founder and portfolio manager \\ at Sententia Capital Management}

\section{What do being a Navy SEAL and being a value investor have in common?}

Almost everything. Believe it or not, the same skills we used in the military are directly applicable to the investment management business. The main lessons after nearly 10 years were tactical understanding of risk mitigation and execution, strategic application of intelligence fusion and networking, and the nuanced assessment of behavioral analysis and incentives. Mostly, mettle is a differentiator. We walk the line between risk mitigation and outperformance. We invest in value stocks, which is a natural risk mitigator. Deep research and focus on key levers further mitigate the risk as we learn companies. Decision making, sizing, incentive awareness, timing signals - we use these aspects to gain an edge of outperformance.

It's uncomfortable to invest in this manner. That's where the mettle comes in. Some of the best investors have it, and we look to prove ourselves in this environment.

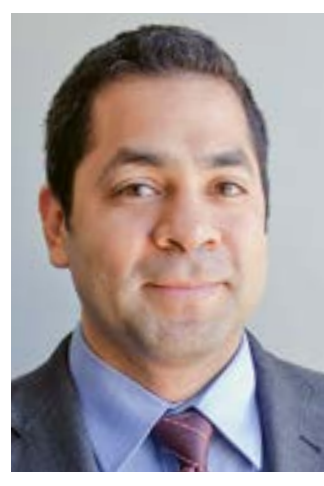

Mike Zapata

\section{I would imagine that these characteristics apply to most careers. How did you decide to start a value- investing shop specifically?}

There were three things I valued while I was in the SEAL Teams: autonomy, responsibility, and accountability. The traits can be found in the fabric of Sententia, as the success depends on our decisions, both to our investment and the firm. We bear the responsibility of growing our partners' investments, and I am accountable to them and the future of the firm, as well as the families of fallen SEALs.

\section{It sounds as though you've been able to garner the attention of some extremely influential value investors. How did you get their attention?}

I want to learn from the best. Columbia [Business School] and the Heilbrunn Center for Graham \& Dodd [Investing] provided the opportunity to learn from the best. [Mario] Gabelli, Michael Price, Jean-Marie Eveillard, Bill Millerthese guys have been successful over decades, and I have great respect for their experience. I have kept each of them and others updated over the years about Sententia's progress. They ultimately became general partners in Sententia Capital Management. I consider all of them mentors. And I'll be working to grow their wealth, along with all of my limited partners. 


\section{LEONARDO CARDOSO, CFA}

Portfolio manager and investment strategist

at Israel Discount Bank

A Brazilian infantry officer living in New York City working as a global investment strategist for an international bank-how did you end up with this position?

I will never forget arriving in Castlewood, South Dakota (population 549), from the tropical city of Recife (population 1.5 million) located on the northeast coast of Brazil. As a foreign-exchange student, I expected language confusion, but until then I had never seen letters scrolling in the footer of the TV screen; that piqued my interest. Once I learned the significance and meaning of those letters, I decided to

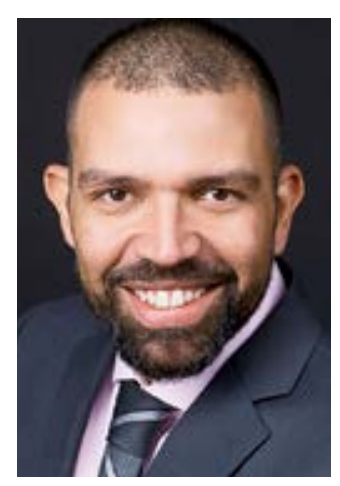

Leonardo Cardoso, CFA pursue a career in finance and one day become an investor. The year passed, and I went back to Brazil determined to return to the US and graduate in finance. I did so, at the University of Florida, but not before another amazing experience serving in the Brazilian Army. In summary, to get here wasn't easy and to stay here will probably be even harder, but I have a goal to chase and a track record of successfully dealing with challenges.

Do you think the skills taught through military service help give veterans the discipline required to study for and pass each level of the CFA exam, or is it case dependent as it is with the general population of exam takers? I think veterans are in a unique position to capitalize on some of the skills acquired during service. After deciding to sit for the Level I exam, I turned to the organizational skills necessary to successfully execute a "multi-year mission." Planning my studying sessions and approaching them with intention helped me to avoid spending unnecessary time on topics that I felt comfortable with. Prioritizing to learn the most important topics optimized the committed time. Time management was crucial, as I needed to split my time between studying, family, teaching an introduction to finance course at NYU, and working full-time. Last but not least, detail orientation helped to avoid skipping over topics deemed "unimportant," as well as avoid little missteps such as incorrectly marking the answer sheet and sabotaging an otherwise successful mission. Unless a civilian had military parents or went to boarding school, the organizational skills mentioned above were probably acquired over time; recruits, however, quickly learned the importance of them from a drill sergeant during boot camp.
IN SUMMARY, TO GET HERE WASN'T

EASY AND TO STAY HERE WILL

PROBABLY BE EVEN HARDER, BUT

I HAVE A GOAL TO CHASE AND A

TRACK RECORD OF SUCCESSFULLY DEALING WITH CHALLENGES.

As a charterholder, what parallels do you draw between the CFA Institute Code of Ethics and the principles that were instilled in you during your time in service?

The very first requirement in the Code of Ethics states, "Act with integrity, competence, diligence, respect, and in an ethical manner." That is true nowhere more than the military. Integrity means we make good decisions even when others aren't looking over our shoulder. Competence can in some cases mean the difference between life and death, as good decisions have to be made instantly. Respect is obviousma'am, sir, saluting, etc.-and is often the number one word associated with military service. Ethical manner means we hold ourselves to a higher standard than simply following the law. In the high-stakes world of the military, the system would be broken if these principles weren't adhered to, and in the high-stakes world of finance, we've seen entire economies collapse when these principles aren't adhered to as well. Unfortunately, history provides us with clear examples of both when these standards are not met, and it is no coincidence that both the military and CFA Institute place such a high level of importance on them in every single decision we make.

\section{KYLE J. WHITE}

Vice president and fixed-income specialist at Bank of America Merrill Lynch

As one of only 75 people alive today who currently holds the highest decoration in the United States military (Medal of Honor), you could likely work in any field or for any company you want. How did you decide on a career in finance?

Although the Medal of Honor has provided many opportunities, my decision to pursue a career in finance came before the award. I transitioned out of active duty and went directly to school to earn my degree. It was not until after I started my first job in the finance field that I received the call from the president of the United States about my award being approved by him.

How would you compare your experience in the military with your current role?

I do see differences in the two roles. There are also similarities. The stress of combat is hard to explain; it has to be experienced firsthand. One of the memories I have about the 
few times I was in actual combat is that afterwards, when the adrenaline wears down, you feel absolutely exhausted. I remember feeling mentally and physically drained. The only thing I wanted to do was eat and go to sleep, although that was often not an option. That is also something I notice that is similar to my current role. There are days in my current position that leave me mentally drained; I am not stating that as a negative but, rather, as a positive. Depending on what the market is doing, my job can be very fast paced and exciting. Sometimes, trades are big, and when the dollar amounts approach the millions, you can get a bit of an adrenaline rush, which is the type of environment that members of the military are made to thrive in. We are taught to think on our feet and to deal with stress in different ways. I have no doubt that the training I received in the military has contributed to my success in my current position; I think that is why I enjoy what I do so much. There are exciting times, with the major differences being that I am not being shot at and I am not having to do so many pushups on a daily basis.

\section{After the financial markets collapsed in $\mathbf{2 0 0 8}$ and public perception of Wall Street was arguably tarnished, many companies were looking for a way to rebrand their image. Do you think these companies hire "heroes" because they are looking to acquire instant credibility, or are there other attributes they seek in those who have exemplified bravery and selfless service in a past life?}

After spending a few years interacting with the finance world, I can tell you that firms like Bank of America are hiring veterans due to the valuable skills that they bring to the table. When I am able to speak to transitioning veterans, I always emphasize that they have what I call a "bag of skills" that instantly separates them from their peers. What I mean by that is the simple attributes each service member gains through their years of service to our country. It is often simple things like accountability, honesty, integrity, responsibility, determination, loyalty, and just a general good work ethic. I will admit some of those attributes are based on a veteran's overall motivations and goals in life, but generally, each veteran brings their own "bag of skills" to each firm they work with. They have valuable lessons on leadership that are often learned the hard waylessons that any company would be smart to recognize and deploy within their framework. I have had the opportunity

\section{THERE ARE EXCITING TIMES, WITH \\ THE MAJOR DIFFERENCES BEING \\ THAT I AM NOT BEING SHOT AT AND I AM NOT HAVING TO DO SO MANY PUSHUPS ON A DAILY BASIS.}

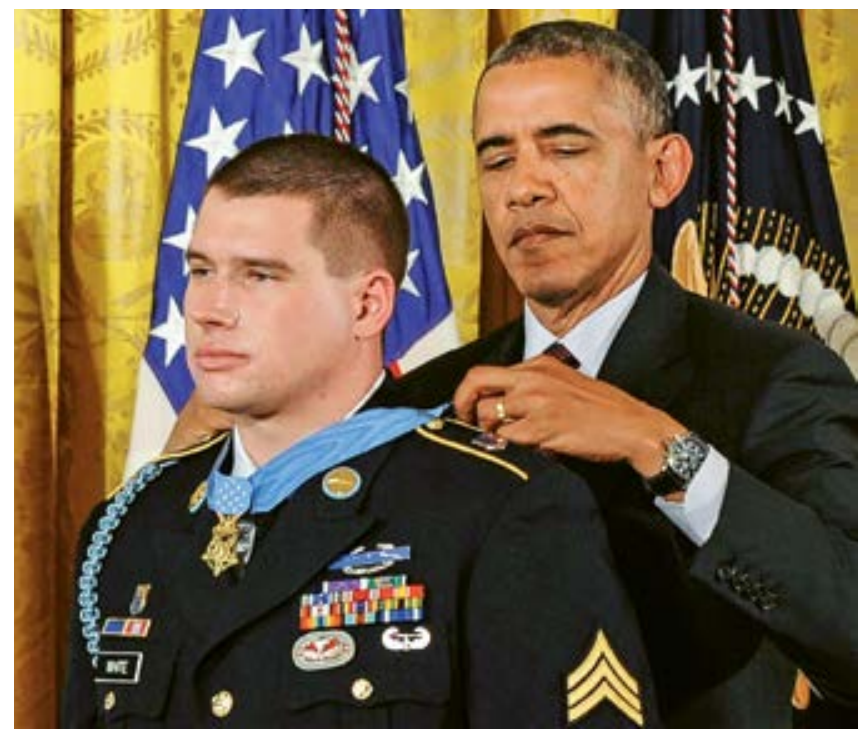

US President Barack Obama awarded Kyle J. White the Medal of Honor on 13 May 2014.

to speak with incoming veterans at our firm more than a few times, and it is always great to hear about everyone's story of service and how they arrived here at the bank. While I may not be able to speak for all the firms on Wall Street on their hiring intentions, I can say that veterans who gain employment will undoubtedly become important assets regardless of their positions.

\section{What would you tell somebody who may feel intimidated about transitioning into this competitive industry against his or her peers with several more years of direct experience?}

The one piece of advice I continue to give to veterans looking to transition into any industry is that they must not be afraid to sell themselves. This is a difficult concept to grasp for some, including myself. It took me quite a few interviews before I was able to say what I really thought I could bring to a company and why I was a more valuable asset than other candidates. I am not saying that I went into the interview and proudly stated that I would be their greatest employee to ever grace their halls, but instead, I stated what the military gave me that I would not otherwise possess had I not served. Those traits, regardless of your branch of service or your position in the military, will set you apart.

It is important to be able to translate what you did in the military in relatable terms to the person who is interviewing you. You may have been in charge of a platoon in combat, but what does that mean for your skills in the workplace? Are you a leader? Can you be a follower? Can you learn a new task and instruct a team on how to be proficient as well? Can you solve problems with little or no instruction? It takes hard work for a veteran to polish their interviewing skills and hone the points I just mentioned, but the effort is worth it.

Lance Widner, CFA (USNR), is senior director of the Private Equity Group at Oppenheimer \& $\mathrm{Co}$. and co-founder of the NYSSA Veterans Roundtable. Matt Noll, CFA (former USN), is a senior manager at Ernst \& Young and co-founder of the NYSSA Veterans Roundtable. 